19 Revue d'histoire du XIXe siècle

Société d'histoire de la révolution de 1848 et des

révolutions du XIXe siècle

$24 \mid 2002$

Varia

\title{
La Commune de 1871, Colloque de Précieux et Montbrison (Loire). Programme
}

\section{(2) OpenEdition}

\section{Journals}

Édition électronique

URL : http://journals.openedition.org/rh19/412

DOI : $10.4000 /$ rh19.412

ISSN : $1777-5329$

Éditeur

La Société de 1848

Édition imprimée

Date de publication : 1 juin 2002

Pagination : 266-268

ISSN : 1265-1354

\section{Référence électronique}

"La Commune de 1871, Colloque de Précieux et Montbrison (Loire). Programme », Revue d'histoire du

XIXe siècle [En ligne], 24 | 2002, mis en ligne le 04 juin 2003, consulté le 15 septembre 2020. URL

http://journals.openedition.org/rh19/412

Ce document a été généré automatiquement le 15 septembre 2020.

Tous droits réservés 


\section{La Commune de 1871, Colloque de Précieux et Montbrison (Loire). Programme}

organisé par l'Association des Amis de Benoît Malon et l'Université de Saint-Etienne les samedi 15 mars et dimanche 16 mars 2003 sous la présidence de Michelle Perrot et de Jacques Rougerie Samedi 15 mars 2003, salle des fêtes de Précieux 9h Ouverture du colloque par Michelle Perrot et Jacques Rougerie Présidente de séance : Michelle Perrot 9 h30 Jacques ROUGERIE, Maître de Conférences honoraire à l'Université de Paris : $L a$ Commune de 1871 : état de la question. 10h Pierre LEVEQUE, Professeur émérite à l'Université de Bourgogne) : Les courants politiques de la Commune de Paris. 10h30 Odile KRAKOVITCH (archiviste, Archives Nationales) : Clémenceau et les femmes de Montmartre : un avant-signe?

11h André COMBES (agrégé d'histoire, Directeur de l'Institut d'Etudes et de Recherches Maçonniques) : La Franc-Maçonnerie parisienne en 1871 : conciliateurs et Communards. $12 \mathrm{~h}$ pose de la première pierre du bâtiment Benoît Malon du lycée agricole de Précieux $12 \mathrm{~h} 30$ repas au lycée agricole de Précieux. Interprétation par l'Association Cabaret du "Chant socialiste" de Benoît Malon.

$14 \mathrm{~h}$ retour à la salle à la salle des fêtes

Président de séance : Marc Vuilleumier

14h30 Philippe DARRIULAT, agrégé d'histoire, docteur en histoire, professeur au lycée d'Aubervilliers) : Le sentiment patriotique des Communards, dernière manifestation d'une tradition de la Gauche Républicaine?

15h Claude LATTA, docteur en histoire, Président de l'Association des Amis de Benoît Malon) : Benoît Malon pendant la Commune de 1871.

15h30 Robert TOMBS, Professeur au Saint John's College de Cambridge : La semaine sanglante (titre provisoire).

Président de séance : Jacques Rougerie 
16h15 Michelle PERROT, Professeur émérite à l'Université de Paris VII Denis Diderot) : George Sand, une républicaine contre la Commune.

16h45 Michel CORDILLOT (Professeur à l'Université de Paris VIII-Saint Denis) : Autour de l'appel aux travailleurs des campagnes : les réactions de la France rurale à la Commune:

l'exemple de l'Yonne.

17h15 Charles-Henri GIRIN, professeur d'histoire au lycée de Montbrison, secrétaire de l'Association des Amis de Benoît Malon, rédacteur en chef du bulletin : La Commune de Saint-Etienne.

17h45 Jean LORCIN, Professeur émérite à l'Université de Lyon II : Jacques Vacher, le garibaldien, et la Commune de Saint-Etienne.

$18 \mathrm{~h} 30$ réception à la mairie de Précieux par M. le maire de Précieux et les membres du conseil municipal

20h dîner au lycée agricole de Précieux

Dimanche 16 mars, Montbrison, Centre social, place Pasteur

Président de séance : Odile Krakovitch

9h Marc VUILLEUMIER, Chargé de cours honoraire à l'Université de Genève : L'exil des Communeux en Suisse.

9h30 Laure GODINEAU, Maître de Conférences à l'Uuniversité de Paris : La vision de la Commune à travers les débats pour l'amnistie.

10h Danielle DONNET-VINCENT (Docteur en histoire, Paris, New York) : Mémoire /

Mémoires : de la réalité à la fiction. La transmission de la mémoire d'un déporté de la Commune:

d'un passé occulté à un passé réapproprié.

Président de séance : Jean Lorcin

10h45 Danielle TARTAKOWSKY, Professeur à l'Université de Paris-VIII : Mémoires de la Commune : résurgences et refoulements.

11h15 Didier NOURRISSON (Professeur d'histoire contemporaine, IUFM Lyon-SaintEtienne, Directeur de l'Institut de Recherche sur l'Enseignement de l'Histoire et de la Géographie) La Commune enseignée au cours des Républiques.

Présidente de séance : Danielle Tartakowski

14h Alain DALOTEL, historien, membre du bureau des Amis de la Commune de Paris :

Benoit Malon : le retour (1880-1893).

14h30 Bruno ANTONINI, professeur de philosophie, Docteur en philosophie, Paris : La Commune, Jaurès et l'idée d'auto-émancipation du prolétariat. Théorie du pouvoir et révolution sociale.

15h Jean-Bernard VRAY, Professeur de littérature française, université Jean Monnet de Saint-Etienne et IUFM Lyon-Saint-Etienne) : La Commune, histoire et fiction : Le Cri du peuple de Jean Vautrin et son adaptation en BD par Tardi. 15h30 Pascal CHAMBON, Docteur en Histoire, professeur d'Histoire au collège Victorde-Laprade de Montbrison : la Commune et la fin de la garde nationale 16h Conclusion du colloque 